\title{
Can the Theory of Planned Behavior help explain attendance to follow-up care of childhood cancer survivors?
}

Julia Baenziger ${ }^{1}$, Katharina Roser ${ }^{1}$, Luzius Mader ${ }^{1}$, Salome Christen ${ }^{1}$, Claudia E Kuehni ${ }^{2}$, Fabienne Gumy-Pause ${ }^{3}$, Eva Maria Tinner ${ }^{4}$, Gisela Michel ${ }^{1,2^{*}}$

${ }^{1}$ Department of Health Sciences and Health Policy, University of Lucerne, Frohburgstrasse 3,6002 Lucerne, Switzerland; julia.baenziger@unilu.ch, katharina.roser@unilu.ch, luzius.mader@unilu.ch, salome.christen@unilu.ch,gisela.michel@unilu.ch

${ }^{2}$ Institute of Social and Preventive Medicine, University of Bern, Finkenhubelweg 11, 3012 Bern, Switzerland; claudia.kuehni@ispm.unibe.ch

${ }^{3}$ Department of Pediatrics, Onco-Hematology Unit, Geneva University Hospitals, Geneva, Switzerland; fabienne.gumypause@hcuge.ch

${ }^{4}$ Division of Pediatric Hematology/Oncology, University Children's Hospital Bern, Inselspital, 3010 Bern, Switzerland; eva.tinner@insel.ch

Short title: Follow-up attendance of cancer survivors: Theory of Planned Behavior

Keywords: cancer, oncology, pediatric, Theory of Planned Behavior, survivor, follow-up care, attendance, cancer registry

*Corresponding author: Gisela Michel, Department of Health Sciences \& Health Policy, University of Lucerne, Frohburgstrasse 3, 6002 Lucerne, Switzerland

Ph:+41 41229 5955; Fax: +41 41229 5635; E-mail: gisela.michel@unilu.ch

Funding: Swiss National Science Foundation Ambizione Fellowship No. PZ00P3_121682/1 and PZ00P3-141722 to GM; Swiss National Science Foundation Grant No.

100019_153268/1; Swiss Cancer League Grant No. KLS-3412-02-2014

\section{Counts:}

Abstract word count: 229/250

Total word count: 4'492/4500

Number of references: $40 / 40$

Number of tables and figures: $3 / 4$

Supplemental items: 4

Formatted for: Psycho-Oncology

Version: 23.02.2018

This article has been accepted for publication and undergone full peer review but has not been through the copyediting, typesetting, pagination and proofreading process which may lead to differences between this version and the Version of Record. Please cite this article as doi: 


\section{ABSTRACT}

Objective: Childhood cancer survivors are at high risk for late effects. Regular attendance to long-term follow-up care is recommended and helps monitoring survivors' health. Using the Theory of Planned Behavior (TPB) we aimed to 1) investigate the predictors of the intention to attend follow-up care, and 2) examine the associations between perceived control and behavioral intention with actual follow-up care attendance in Swiss childhood cancer survivors.

Methods: We conducted a questionnaire survey in Swiss childhood cancer survivors (diagnosed with cancer aged <16 years between 1990 and 2005; $\geq 5$ years since diagnosis). We assessed TPB-related predictors (attitude, subjective norm, perceived control), intention to attend follow-up care, and actual attendance. We applied structural equation modeling to investigate predictors of intention, and logistic regression models to study the association between intention and actual attendance.

Results: Of 299 responders (166 (55.5\%) females), 145 (48.5\%) reported attending followup care. We found that subjective norm, i.e. survivors' perceived social pressure and support, (Coef.0.90, p<0.001) predicted the intention to attend follow-up; attitude and perceived control did not. Perceived control (OR=1.58, 95\%Cl:1.04-2.41) and intention to attend follow-up (OR=6.43, 95\% Cl:4.21-9.81) were positively associated with attendance.

Conclusions: To increase attendance, an effort should be made to sensitize partners, friends, parents and health care professionals on their important role in supporting survivors regarding follow-up care. Additionally, interventions promoting personal control over the follow-up attendance might further increase regular attendance. 


\section{BACKGROUND}

Regular attendance to long-term follow-up care after childhood cancer is important because adverse health-related consequences may occur many years after treatment [1]. Survival rate after childhood cancer has increased steadily in the past decades with more than $80 \%$ surviving $\geq 5$-years [2, 3]. However, cancer and its treatment can cause burdensome late effects such as impairment of pulmonary, auditory, endocrine, cardiac and neurocognitive functions [4]. Two thirds of childhood cancer survivors aged 5-19 years suffer from at least one chronic health condition [5]. Around age 45, this prevalence is nearly $90 \%[4,5]$. Moreover, late effects may also include worsened social [6] and psychological outcomes [7, 8]. Detecting potential late effects early is crucial to decrease survivors' burden [5], and follow-up care plays an essential role in monitoring survivors' overall health $[1,5]$.

Yet, the majority of long-term survivors do not attend follow-up [9, 10]. In Switzerland, about $23 \%$ of all adult survivors regularly attend follow-up [9] and $56 \%$ among adolescent survivors [11]. More than 10 years post-diagnosis, only $17 \%$ of survivors with moderate and $32 \%$ with severe late effects had regularly received follow-up care [12]. Also in the US, follow-up attendance is of concern and attendance rates have remained low, even after implementing guidelines and efforts to increase education and awareness of late effects [10].

Younger survivors [9], females [13, 14], those with higher socio-economic status [14], and those with lower educational background [9] were shown to be more likely to attend followup care. In the US and Canada, having private insurance [10] and smaller distance to hospital $[13,14]$ have been associated with increased attendance. Among cancer-related characteristics, survivors who had been diagnosed at an older age [9], had been treated with higher intensity [10, 14], experienced relapse [9, 13] or those who had leukemia or lymphoma [13] showed higher attendance rates than their peers. Meanwhile, decreased attendance was observed with longer time since diagnosis and treatment $[13,15]$ and in survivors' who had a brain tumor [13]. To increase attendance, it is important to identify additional factors which predict follow-up attendance in childhood cancer survivors - other than socio-demographic and cancer related - in order to inform interventions [15]. Psychological factors associated with attendance to follow-up care have rarely been examined. Our previous studies applying the health belief model suggested that perceived barriers hindered actual attendance to follow-up care [9, 11], whereas perceived benefits and beliefs about severity or susceptibility for late effects were not associated with attendance [9]. More recent health behavior theories might help to explain follow-up attendance further.

This article is protected by copyright. All rights reserved. 
The Theory of Planned Behavior (TPB) developed in 1985 has become one of the most influential models in predicting a diverse range of health behaviors $[16,17]$. The intention to perform a specific behavior is understood to result from three underlining constructs: Attitude, subjective norm, and perceived behavioral control (perceived control). Attitude is composed of personal evaluations of the negative and positive consequences of the behavior. Subjective norm incorporates individuals' perceived social pressure to perform the behavior. For instance, the estimation that parents expect them and would like them to attend follow-up care. Perceived control reflects whether a person feels able to enact the behavior; it includes the actual control necessary to perform the behavior and how confident the person feels to perform this behavior. It is expected that a positive attitude, the perception that close friends, family and other important people support the behavior, and the expectation that one has personal control over a behavior will increase the intention to actually perform the behavior. Moreover, with higher intention, people are expected to be more likely to perform the behavior. Because a certain degree of actual control over the behavior is necessary for behavioral performance, perceived control is also understood to have a direct impact on behavioral performance itself (Figure 1).

We used the TPB as a theoretical framework to study follow-up care attendance in Swiss childhood cancer survivors. We aimed to 1 ) investigate the predictors of the intention to attend follow-up care and 2) examine the associations between perceived control and behavioral intention with actual follow-up care attendance.

\section{METHODS}

\section{Sampling and procedure}

In Switzerland, childhood cancer patients ( $<21$ years) are centrally registered in the Swiss Childhood Cancer Registry (SCCR) [18, 19]. All survivors in the SCCR who were Swiss residents at diagnosis, diagnosed with cancer $<16$ years between 1976 and 2005 and who had survived cancer for $\geq 5$ years were invited to participate in the Swiss Childhood Cancer Survivor Study (SCCSS) baseline questionnaire survey conducted between 2007-2009 [6]. For the current study, a follow-up questionnaire focusing on attendance and satisfaction with follow-up care and psychological outcomes was sent to survivors who had participated in the baseline questionnaire. We only included survivors diagnosed after 1990, because they are not usually followed up for more than 10 years after diagnosis in Switzerland. Furthermore, only adult survivors (aged $\geq 18$ years) at time of study between $2010-2012$ were eligible. We sent a cover letter along with study information, the questionnaire and a pre-paid return 
envelope to all eligible survivors with a valid address. After two months, non-responders received a reminder with a second copy of the questionnaire. Ethics approval was granted through the Ethics Committee of the Canton of Bern to the SCCR and SCCSS (KEK-BE: $166 / 2014)$

\section{Measurements}

\section{Variables according to the Theory of Planned Behavior}

To assess predictors (attitude, subjective norm, perceived control) and intention we developed questions according to the TPB manual by Francis and colleagues [20] (Supplementary Table S1). We used 7 point-Likert scales ranging from 1 to 7 , with 1 representing the most positive, and 7 the most negative value on each indicator. Indicators were used reverse-coded for analysis with higher scores indicating more positive attitude towards follow-up care, more supportive subjective norm, more perceived control, and higher intention to attend follow-up, respectively. For follow-up attendance we generated a binary variable: attenders (responses 1 "I regularly attend follow- up" and 2 "I irregularly attend follow- up") and non-attenders ( 3 "Follow-up is completed but I visit my treating doctor when I have questions" and 4 "Follow- up is completed and I never visit my former treating doctor") as previously done [21-23].

\section{Covariates}

\section{Socio-demographic variables}

Sex and language region (German/French/Italian) were extracted from the SCCR. Age at study, migration background (defined as not Swiss citizen, not Swiss citizen since birth or not born in Switzerland), educational achievement (compulsory schooling, vocational training, upper secondary education, university degree) employment status (employed/not employed/in training), and having a partner (yes/no) were derived from the questionnaire.

\section{Cancer-related variables}

From the SCCR, we extracted the following variables: Diagnosis coded according to the International Classification of Childhood Cancer $-3^{\text {rd }}$ edition (ICCC-3) [24]. Treatment coded hierarchically: surgery only, chemotherapy (may have had surgery), radiotherapy (may have had surgery and/or chemotherapy) and stem cell transplantation. Age at diagnosis and time since diagnosis were included as continuous variables, and relapse coded into yes/no. From the questionnaire, we obtained self-reported presence of late effects (yes/no) and second malignancies (yes/no). Additionally, we asked survivors about their fear of detecting late effects, which might be associated with not attending follow-up: When I attend follow-up care, I fear that late effects will be detected (7-point Likert scale: not true at all - very true). 


\section{Statistical Analysis}

All data analyses were performed using Stata 14.0 (StataCorp LP, College Station, TX, USA). To describe and compare participants and non-participants, we used descriptive statistics, chi ${ }^{2}$ tests (categorical variables) and t-tests (continuous variables). Self-reported information for non-participants was obtained from the baseline questionnaire.

\section{Aim 1: Predictors and intention}

We used structural equation modeling to determine associations between predictors and intention. Structural equation modeling has the advantage of using measured indicators (asked in the questionnaire) to construct latent factors (predictors and intention) and then analyze associations between latent factors. For our analysis, we first built an adequate measurement model and then added structural paths.

\section{Measurement model}

Questionnaire items served as indicators for the four latent factors attitude, subjective norm, perceived control and intention. To determine internal consistency, Cronbach's alpha was used for each factor separately and considered adequate if $\alpha \geq 0.7$ [25]. To see whether indicators loaded on one factor each, we performed principal component factor analysis for each factor separately. Factor loadings $\geq 0.4$ were considered substantial [26]. We then performed confirmatory factor analysis including all latent factors. Modification indices and logical reasoning were used to adjust the model [26, 27].

\section{Structural model}

The paths between attitude, subjective norm, perceived control, and intention are representing the structural model (Figure 1). We fitted the model using maximum likelihood estimation, which takes into account all available data regardless of missing values. To evaluate model fit, we used a set of goodness of fit indices: $\mathrm{chi}^{2}, \mathrm{chi}^{2} / d f$, Root Mean Square Error of Approximation (RMSEA), Standardized Root Mean Square Residual (SRMR) and Comparative Fit Index (CFI) [26, 28].

\section{Aim 2: Perceived control, intention and attendance}

We used multivariate logistic regression to determine the association between perceived control and follow-up attendance, and the association between intention and follow-up attendance. For perceived control and intention, we used the computed factor scores, which were based on measured indicators during principal component factor analysis. 


\section{Covariates}

Socio-demographic and cancer-related variables were included in the structural equation modeling and regression analyses. Only variables significantly associated with follow-up intention or attendance in univariable regression analysis $(p \leq 0.05)$ were included in the respective final models. Sex and age at study were included in all models.

\section{RESULTS}

\section{Study population}

Of 716 eligible survivors, $687(100 \%)$ could be contacted, and $13(1.9 \%)$ refused participation. Of $320(46.6 \%)$ responders, $3(0.4 \%)$ survivors whose parents filled out the questionnaire and $18(2.6 \%)$ participants who did not complete the TPB section were excluded (Supplementary Figure 1). Among the 299(43.5\%) participants included in analysis, 166 were female $(55.5 \%$, Table 1). Mean age at study of survivors was 25.1 years, with a mean time since diagnosis of 16.3 years. Most survivors were diagnosed with leukemia (37.5\%), lymphomas (18.4\%), and central nervous system tumors (11.4\%). Socio-demographic and cancer-related characteristics of participating and non-participating survivors are described in Table 1. Participants were more likely to be female and to have had chemotherapy and radiotherapy.

\section{Aim 1: Predictors - Intention}

\section{Measurement Model}

Internal consistency was strong for attitude (Cronbach's alpha $\alpha=0.82$ ), subjective norm $(\alpha=0.90)$, and intention ( $\alpha=0.99)$. Perceived control showed weak internal consistency $(\alpha=0.35)$. Principal component factor analysis revealed high factor loadings $(0.56-0.99)$ for all indicators on their respective factor (attitude, subjective norm, perceived control or intention), except indicator PC3 for perceived control loading negatively on the factor $(-0.15)$ (Supplementary Table S2) Therefore, indicator PC3 was removed from perceived control, which raised internal consistency to $\alpha=0.72$. Performing confirmatory factor analysis, modification indices (MI) suggested covariation of two pairs of error terms within the factor attitude, namely between indicator A1(meaningful-superfluous) and indicator A2(good-bad) $(\mathrm{MI}=67.4)$, as well as between indicator $A 3$ (pleasant-unpleasant) and indicator A4(interesting-boring) ( $\mathrm{Ml}=63.2)$. Logical reasoning supports freeing co-variances between those pairs: the first two indicators reflecting the importance of attending follow-up care, and the latter two how comfortable the follow-up procedure is. An unobserved common antecedent for these indicators can be assumed [29, 30].

This article is protected by copyright. All rights reserved. 


\section{Structural Model}

Among the three predictors, supportive subjective norm was significantly associated with higher intention (coef $=0.90 ; p<0.001$, Table 2). Attitude (coef $=0.02, p=0.810$ ) and perceived control (coef $=0.08 ; p=0.314$ ) showed weak and non-significant associations. Among covariates, women (coef $=0.07, p=0.020$ ) and survivors with more time since diagnosis (coef $=0.71, p=0.048$ ) showed a higher intention to attend follow-up. Overall, predictors and covariates explained $90.2 \%$ of the variance in intention to attend follow-up, with the final model showing acceptable fit $\left(\chi^{2} / d f=2.23, \mathrm{RMSEA}=0.064 \mathrm{SRMR}=0.055 ; \mathrm{CFI}=0.956\right)$.

\section{Aim 2: Perceived control, intention and attendance}

In the multivariable regression model, higher perceived control $(\mathrm{OR}=1.72,95 \% \mathrm{Cl}: 1.10-2.70)$ and higher intention (OR=6.73,95\%Cl:4.28-10.55) were associated with actual attendance (Supplementary Table S3). Neither socio-demographic nor cancer-related co-variates were associated with follow-up attendance.

\section{DISCUSSION}

Our study showed that supportive subjective norm was most strongly associated with survivors' higher intention to attend follow-up care. Women and survivors with more time since diagnosis also showed a higher intention. With higher intention, survivors were more likely to attend follow-up care. Attendance was also greater in survivors who perceived to have control over their follow-up attendance.

\section{Comparison with other studies}

\section{Aim 1: Predictors - Intention}

We found that if partners, peers and family underline the importance of follow-up care and express that they expect the survivor to attend follow-up, survivors are more likely to show a higher intention to attend. We previously observed that survivors whose parents believed follow-up care can help to detect late effects were more likely to attend [22]. A UK study reported that some parents perceived follow-up care as "minimal and inconsequential" (p.2884) [31]. This is of concern, as it might result in lower parental support. Furthermore, some survivors reported that they play down the importance of follow-up care, and that discontinuing care was one of their strategies to achieve a normal life [31]. This further underlines that subjective social norm plays an important role when it comes to follow-up care and thus involving the survivors' immediate social support network is essential. 


\section{Aim 2: Perceived control, intention and attendance}

Our findings indicate that survivors with higher perceived control are more likely to go to follow-up. Studies from the US have shown that survivors with public insurance - as compared to those with private - [13] were less likely to attend follow-up. Public insurance in the US might cover less of the costs for follow-up care, decreasing control over attendance for someone with limited financial resources. Further, greater distance [13, 14] from hospital was associated with non-attendance. Travel expenses and increased travel time require more resources, decreasing control over the behavior. For instance, survivors need to obtain longer leave of absence from work and/or organize care for their children in order to visit follow-up clinics. In Switzerland, health insurance is mandatory and distances are generally short due to the country's size. Actual control may therefore be high, provided survivors know where to obtain follow-up care after being discharged from the children's' hospital. This might explain why perceived control was not associated with intention, but facilitated actual attendance. Earlier studies found women to be more likely to attend follow-up care [13, 14]. We found women to be more likely to have a higher intention to attend follow-up care than men. However, we found no differences between men and women in actual attendance. Women might perceive and/or encounter more obstacles when it comes to organizing time for follow-up care, such as responsibilities in childcare. One of our earlier investigations showed that perceived barriers hindered actual attendance [9].

Contrary to previous studies [6, 8], survivors' intention increased with more time since diagnosis. Survivors might be aware of the importance of follow-up care as reflected in the elevated scores in attitude. Further, with more time since diagnosis, survivors are more likely to experience late effects and might feel the urge to schedule a follow-up appointment. However, they might be hindered due to lacking support, resources and follow-up clinics.

\section{Clinical implications}

Promotional interventions to increase intention and actual follow-up attendance should focus on improving subjective norm and enhancing perceived control. A first step would be to raise awareness among health care professionals, families, partners and friends on the importance of their support regarding the survivors' follow-up care. Providing families and friends with information on risk of late effects and their possible consequences may help them to actively express their opinions about follow-up care and emphasize its value. A great majority of parents has reported information needs, especially on late effects [32]. Only when close ones understand the importance of continuing care, they may adequately support the survivor. Besides mobilizing social networks to promote supportive subjective norms, useful 
strategies may include role modeling and behavioral journalism [33]. For instance, authentic interviews with survivors attending follow-up care spread through the media might assist in highlighting the benefits of long-term follow-up care.

A recent study explored and demonstrated the usability of a text-messaging service to improve the receipt of follow-up care by childhood cancer survivors [34]. The system included reminders and provided suggestions for community resources. Participants reported feeling empowered to actively manage their survivorship care with the health care team. Similar interventions may promote perceived control and encourage attendance. Furthermore, a Survivorship Passport is currently being introduced in Switzerland. The Passport contains information on past treatments and potential late effects, as well as personalized recommendations for follow-up care according to the latest guidelines [35]. Having such a structured outline might help survivors' to have the necessary information to organize the recommended appointments autonomously [36].

Maintaining and increasing easily accessible follow-up clinics throughout Switzerland may further increase perceived and actual control, which might help improve attendance. At present, the first interdisciplinary long-term follow-up clinics in Switzerland are in their early implementation phase. Necessary screenings are scheduled on a single day including discussion of health status, treatment recommendations and an individualized survivorship care plan. This particular setting might facilitate attendance, as required time and travelling are reduced.

In earlier studies, we have shown that women rated multidisciplinary models for follow-up care higher than men [21]. Increasing choice and flexibility of environmental support has been reported as successful strategy to optimize perceived control [37]. Giving survivors the choice for their preferred model of follow-up care might therefore further empower survivors and increase attendance [21, 23].

\section{Limitations and strength}

In our study, response rate to the TPB-questions was relatively low (43.5\%). Women and survivors treated with more intense treatments were more likely to participate. Furthermore, survivors currently attending follow-up care may be more interested in participating as the survey particularly focused on follow-up care. This could explain why participants in our study showed higher attendance rates (41.8\% regular attendance) than reported in previous studies (23\% resp. 19\%) [9, 12]. Subjective norm and perceived control may be the most influential factors for attendance in our sample, but it is possible that attitude is driving 
intention formation for survivors not participating in this survey. However, a recent analysis of data from the SCCSS showed that nonresponse bias may only play a minor role, and that results can be generalizable for clinical implementation [38]. Another limitation is using current follow-up attendance as a proxy measure for future follow-up attendance, as prospective data collection on attendance was not available. We do not know whether follow-up attendance will be stable over time. We have seen in Swiss childhood cancer survivors that attendance decreases with more time passing [22]. We only included relatively young survivors (all below age 40), and attendance may differ in older survivors. Further, we did not take into account the degree of health-related self-efficacy [39] - the extent to which a survivor believes s-he is capable of actually going to follow-up care. Survivors' perception of self-efficacy is inherently linked to their perceived control over the behavior. Including this measure in future studies might help to disclose more precise targets for interventions.

A major strength of our study is the population-based sample of adult childhood cancer survivors. Moreover, the findings are further strengthened by observing very similar patterns regarding follow-up behavior in Swiss adolescent and young adult cancer survivors [40]. Applying the recognized theoretical framework on a survivor population helped us identify survivors' perceptions regarding follow-up care. This information can help in developing and tailoring future interventions to increase attendance of childhood cancer survivors.

\section{Conclusion}

Our study showed that the TPB helps in explaining follow-up attendance of childhood cancer survivors. We found that survivors' perceived social pressure to attend follow-up care increased their intention to attend follow-up care. Furthermore, if survivors felt more in control towards attending follow-up care, they were more likely to attend. An effort should be made to sensitize partners, friends, parents and health care professionals on their important role regarding the survivor's follow-up care. Promoting visibility of environmental aspects such as social support and easy organization of follow-up care may help increasing attendance.

\section{Acknowledgements}

Special thanks go out to survivors for participating in our survey, to the Swiss Childhood Cancer Survivor Study team as well as the Swiss Childhood Cancer Registry team.

\section{Funding}

This study was supported by the: Swiss National Science Foundation Ambizione grant No. PZ00P3_121682/1 and PZ00P3-141722 to GM, Swiss Cancer League grant No. KLS-341202-2014.

\section{Conflict of interest statement}

The authors have no conflict of interest to declare. 


\section{References}

1. Oeffinger, KC. Longitudinal Cancer-related Health Care for Adult Survivors of Childhood Cancer. Commissioned Report, Washington, DC: Institute for Medecine; 2002. Available from:

http://www.iom.edu/ /media/Files/Activity\%20Files/Disease/NCPF/BackgroundPaperLongitu dinalCancerRelatedHealthCareforAdultSurvivorsofChildhoodCancer.pdf.

2. Schindler, M, Belle, FN, Grotzer, MA, von der Weid, NX, Kuehni, CE Swiss Paediatric Oncology, G. Childhood cancer survival in Switzerland (1976-2013): Time-trends and predictors. Int J Cancer 2017; 140(1):62-74

3. Smith, MA, Altekruse, SF, Adamson, PC, Reaman, GH Seibel, NL. Declining childhood and adolescent cancer mortality. Cancer 2014; 120(16):2497-506.

4. Hudson, MM, Ness, KK, Gurney, JG, Mulrooney, DA, Chemaitilly, W, Krull, KR, et al. Clinical ascertainment of health outcomes among adults treated for childhood cancer. JAMA 2013; 309(22):2371-81.

5. Phillips, SM, Padgett, LS, Leisenring, WM, Stratton, KK, Bishop, K, Krull, KR, et al. Survivors of childhood cancer in the United States: prevalence and burden of morbidity. Cancer Epidemiol Biomarkers Prev 2015; 24(4):653-63.

6. Font-Gonzalez, A, Feijen, EL, Sieswerda, E, van Dulmen-den Broeder, E, Grootenhuis, $\mathrm{M}$, Maurice-Stam, $\mathrm{H}$, et al. Social outcomes in adult survivors of childhood cancer compared to the general population: linkage of a cohort with population registers. Psychooncology 2015; doi:10.1002/pon.4040.

7. Zeltzer, LK, Recklitis, C, Buchbinder, D, Zebrack, B, Casillas, J, Tsao, JC, et al. Psychological Status in Childhood Cancer Survivors: A Report From the Childhood Cancer Survivor Study. J Clin Oncol 2009; 27(14):2396-2404.

8. Michel, G, Rebholz, CE, von der Weid, NX, Bergstraesser, E Kuehni, CE. Psychological distress in adult survivors of childhood cancer: the Swiss Childhood Cancer Survivor Study. J Clin Oncol 2010; 28(10):1740-48.

9. Michel, G, Kuehni, CE, Rebholz, CE, Zimmermann, K, Eiser, C, Rueegg, CS, et al. Can health beliefs help in explaining attendance to follow-up care? The Swiss Childhood Cancer Survivor Study. Psychooncology 2011; 20(10):1034-1043.

10. Zheng, DJS, K.; Mitchell, H. R.; Kadan-Lottick, N. S. Patterns and predictors of survivorship clinic attendance in a population-based sample of pediatric and young adult childhood cancer survivors. J Cancer Surviv 2016; 10(3):505-513.

11. Lupatsch, JEW, L.; Rueegg, C. S.; Teuffel, O.; Gumy-Pause, F.; Kuehni, C. E.; Michel, G.; Swiss Paediatric Oncology, Group. Follow-up care of adolescent survivors of childhood cancer: The role of health beliefs. Pediatr Blood Cancer 2016; 63(2):318-325.

12. Rebholz, CE, von der Weid, NX, Michel, G, Niggli, FK Kuehni, CE. Follow-up care amongst long-term childhood cancer survivors: A report from the Swiss Childhood Cancer Survivor Study. Eur J Cancer 2011; 47(2):221-229.

13. Barakat, LP, Schwartz, LA, Szabo, MM, Hussey, HM Bunin, GR. Factors that contribute to post-treatment follow-up care for survivors of childhood cancer. J Cancer Surviv 2012; 6(2):155-162. 
14. Nathan, PCA, M.; Pole, J. D.; Hodgson, D.; Guttmann, A.; Sutradhar, R.; Greenberg, M. L. Predictors of attendance at specialized survivor clinics in a population-based cohort of adult survivors of childhood cancer. J Cancer Surviv 2016; doi:10.1007/s11764-016-0522-y.

15. Devine, KA, Viola, A, Capucilli, P, Sahler, OJZ Andolina, JR. Factors Associated With Noncompliance With Long-term Follow-up Care Among Pediatric Cancer Survivors. J Pediat Hematol Onc 2017; 39(3):167-173.

16. Ajzen, I. The theory of planned behaviour: reactions and reflections. Psychol Health $2011 ; 26(9): 1113-27$.

17. Ajzen, I. The theory of planned behavior. Organizational Behavior and Human Decision Processes 1991; 50(2):179-211.

18. Mitter, V, Michel, G, Strippoli, MP, Rueegg, CS, Rebholz, CE, Feller, M, et al. Annual Report of the Swiss Childhood Cancer Registry 2009/2010. Bern: University of Bern, Institute of Social and Preventive Medicine; 2011. Available from: https://www.childhoodcancerregistry.ch/fileadmin/KKR08/uploads/pdf/20110427 Annual Re port FINAL.pdf.

19. Michel, G, von der Weid, NX, Zwahlen, M, Redmond, S, Strippoli, M-PF Kuehni, CE. Incidence of childhood cancer in Switzerland: The Swiss childhood cancer registry. Pediatr Blood Cancer 2008; 50(1):46-51.

20. Francis, JJ, Eccles, MP, Johnston, M, Walker, A, Grimshaw, J, Foy, R, et al. Constructing questionnaires based on the theory of planned behaviour: manual for health services researchers. Newcastle upon Tyne, UK: Centre for Health Services Research; 2004

21. Christen, S, Vetsch, J, Mader, L, Dehler, S, Korol, D, Kuehni, C, et al. Preferences for the organization of long-term follow-up in adolescent and young adult cancer survivors. Support Care Cancer 2016; doi:10.1007/s00520-016-3157-7.

22. Vetsch, JR, C. S.; Mader, L.; Bergstraesser, E.; Rischewski, J.; Kuehni, C. E.; Michel, G.; Swiss Paediatric Oncology, Group. Follow-up care of young childhood cancer survivors: attendance and parental involvement. Support Care Cancer 2016; 24(7):3127-3138.

23. Michel, G, Gianinazzi, ME, Eiser, C, Bergstraesser, E, Vetsch, J, von der Weid, N, et al. Preferences for long-term follow-up care in childhood cancer survivors. Eur J Cancer Care 2016; 25(6):1024-1033.

24. Steliarova-Foucher, E, Stiller, C, Lacour, B Kaatsch, P. International Classification of Childhood Cancer, third edition. Cancer 2005; 103(7):1457-67.

25. Terwee, CB, Bot, SD, de Boer, MR, van der Windt, DA, Knol, DL, Dekker, J, et al. Quality criteria were proposed for measurement properties of health status questionnaires. $J$ Clin Epidemiol 2007; 60(1):34-42.

26. Acock, AC. Discovering Structural Equation Modeling Using Stata, Revised Edition. College Station, Texas: Stata Press 2013.

27. Schermelleh-Engel, $\mathrm{K}$, Moosbrugger, $\mathrm{H}$ Müller, $\mathrm{H}$. Evaluating the Fit of Structural Equation Models: Tests of Significance and Descriptive Goodness-of-Fit Measures. Methods of Psychological Research 2003; 8(2):23-74. 
28. Schermelleh-Engel, KM, H. Evaluating the Fit of Structural Equation Models: Test of Significance and Descriptive Goodness-of-Fit Measures. Methods of Psychological Research Online 2003; 8(2):51.

29. Tomas, JM Oliver, A. Rosenberg's self-esteem scale: Two factors or method effects. Structural Equation Modeling: A Multidisciplinary Journal 1999; 6(1):84-98.

30. Kline, RB. Chapter 7: Assumptions in Structural Equation Modeling. In: Hoyle, RH (ed.), Handbook of structural equation modeling. New York: Guilford Press; 2011. p. 111-125.

31. Earle, EA, Davies, H, Greenfield, D, Ross, R Eiser, C. Follow-up care for childhood cancer survivors: a focus group analysis. Eur J Cancer 2005; 41(18):2882-6.

32. Vetsch, J, Rueegg, CS, Gianinazzi, ME, Bergsträsser, E, von der Weid, NX, Michel, G, et al. Information needs in parents of long-term childhood cancer survivors. Pediatr Blood Cancer 2015; 62(5):859-866.

33. Eldredge, LKB, Markham, CM, Ruiter, RAC, Fernández, ME, Kok, G Parcel, GS. Planning Health Promotion Programs: An Intervention Mapping Approach. 4th. Jossey-Bass; 2016.

34. Casillas, J, Goyal, A, Bryman, J, Alquaddoomi, F, Ganz, PA, Lidington, E, et al. Development of a text messaging system to improve receipt of survivorship care in adolescent and young adult survivors of childhood cancer. J Cancer Surviv 2017; doi:10.1007/s11764-017-0609-0.

35. Beishon, M. Passport to the future: Improving life for survivors of childhood cancer. Cancerworld 2014; March-April: 46-49. Available from: https://www.siope.eu/.../Passportarticle Cancerworld 2014.pdf.

36. Gianinazzi, ME, Essig, S, Rueegg, CS, von der Weid, NX, Brazzola, P, Kuehni, CE, et al. Information provision and information needs in adult survivors of childhood cancer. Pediatr Blood Cancer 2014; 61(2):312-318.

37. Robinson, S Lachman, M. Perceived Control and Behavior Change. In: Reich, W and Infurna, F (ed.), Perceived control: Theory, Research, and Practice in the First 50 Years. New York, USA: Oxford Univeristy Press; 2017. p. 201-229.

38. Rueegg, CS, Gianinazzi, ME, Michel, G, Zwahlen, M, von der Weid, NX, Kuehni, CE, et al. No evidence of response bias in a population-based childhood cancer survivor questionnaire survey - Results from the Swiss Childhood Cancer Survivor Study. PLoS One 2017; 12(5):e0176442.

39. Bandura, A. Health promotion by social cognitive means. Health education \& behavior : the official publication of the Society for Public Health Education 2004; 31(2):143-64.

40. Roser, K, Baenziger, J, Mader, LC, S, Dehler, S Michel, G. Attendance to follow-up care in survivors of adolescent and young adult cancer: application of the theory of planned behaviour. Submitted. 


\section{Tables}

Table 1. Socio-demographic and cancer-related characteristics of participants compared to non-participants.

\begin{tabular}{|c|c|c|c|}
\hline & \multicolumn{2}{|c|}{$\operatorname{sCCS}(n=716)$} & \\
\hline & Participants & $\begin{array}{c}\text { Non- } \\
\text { Participants }\end{array}$ & \\
\hline Variables & $n=299$ & $n=417$ & \\
\hline Socio-demographic & n (\%) & $\mathrm{n}(\%)$ & p-value \\
\hline \multicolumn{4}{|l|}{ Sex } \\
\hline Female & $166(55.5)$ & $182(43.7)$ & 0.002 \\
\hline Male & $133(44.5)$ & $235(56.4)$ & \\
\hline \multicolumn{4}{|l|}{ Language Region } \\
\hline German & $228(76.3)$ & $293(70.3)$ & 0.157 \\
\hline French & $71(23.8)$ & $123(29.5)$ & \\
\hline Italian & $0(0)$ & $1(0.2)$ & \\
\hline \multicolumn{4}{|l|}{ Migration background $^{a}$} \\
\hline None (Swiss) & $251(84.5)$ & $332(82.0)$ & 0.376 \\
\hline Other countries & 46 (15.5) & $73(18.0)$ & \\
\hline \multicolumn{4}{|l|}{ Education $^{\mathrm{a}}$} \\
\hline Compulsory schooling & $64(22.0)$ & & n.a. \\
\hline Vocational training & $165(56.7)$ & & \\
\hline Upper secondary & $38(13.1)$ & & \\
\hline University degree & $24(8.3)$ & & \\
\hline \multicolumn{4}{|l|}{ Employment status $^{\mathrm{a}}$} \\
\hline No & $18(6.1)$ & & n.a. \\
\hline Yes & $177(60.2)$ & & \\
\hline In training & 99 (33.7) & & \\
\hline \multicolumn{4}{|l|}{ Partnership ${ }^{a}$} \\
\hline Yes & $117(39.4)$ & & n.a. \\
\hline No & $176(59.3)$ & & \\
\hline$\square>$ & Mean(SD) & Mean(SD) & p-value \\
\hline Age at study & $25.12(4.31)$ & $25.56(4.32)$ & 0.089 \\
\hline
\end{tabular}

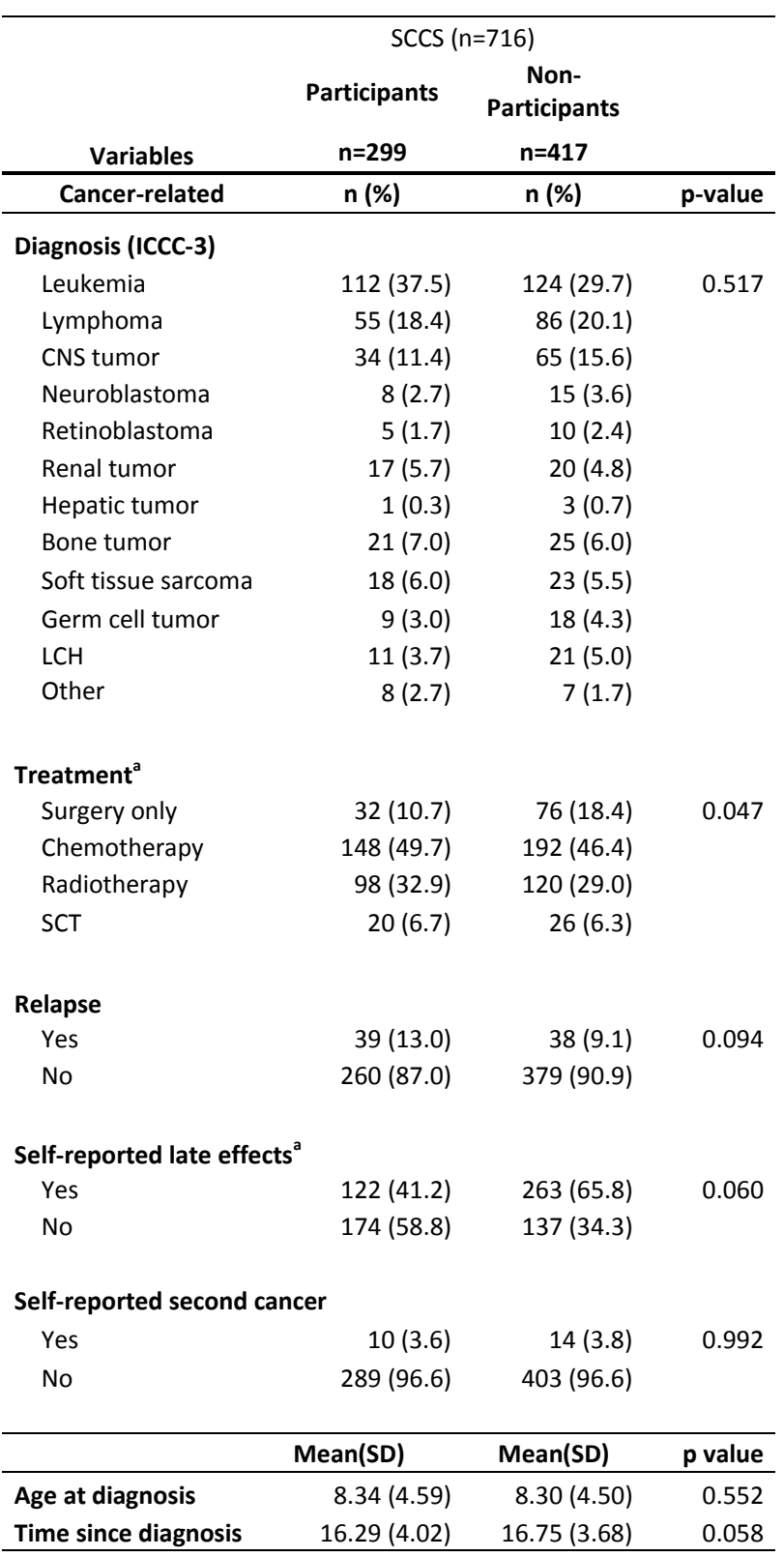

Abbreviations: SCCS, Swiss Childhood Cancer Survivors; ICCC-3, International Classification of Childhood Cancer-Third Edition; CNS, central nervous system; LCH Lanngerhans cell hystiocytosis; SCT, stem cell transplantation; n, number; n.a., not available; SD, standard deviation.

Percentages are based on rounded values and may not add up to $100 \%$. p-values $<0.05$ are indicated in bold.

${ }^{a}$ Missing values; percentages are based on the total number of (non-)participants 
Table 2. Structural equation model (standardized) for the three predictors and intention to attend follow-up care $(n=299)$.

\begin{tabular}{|c|c|c|c|}
\hline Structural model & Standardized coefficient (Cl) & p-value & Robust standard error \\
\hline \multicolumn{4}{|l|}{ Intention } \\
\hline Attitude & $0.02(-0.17 ; 0.19)$ & 0.810 & 0.08 \\
\hline Subjective Norm & $0.90(0.83 ; 0.98)$ & $<0.001$ & 0.04 \\
\hline Perceived Control & $0.08(-0.08 ; 0.26)$ & 0.314 & 0.08 \\
\hline Age at study [years] & $-0.75(-1.51 ; 0.00)$ & 0.050 & 0.41 \\
\hline Sex: female & $0.07(0.01 ; 0.12)$ & 0.020 & 0.03 \\
\hline Education & $-0.01(-0.06 ; 0.05)$ & 0.776 & 0.03 \\
\hline Treatment & $0.05(-0.01 ; 0.10)$ & 0.115 & 0.03 \\
\hline Age at diagnosis [years] & $0.80(0.00 ; 1.61)$ & 0.050 & 0.41 \\
\hline Time since diagnosis [years] & $0.71(0.00 ; 1.42)$ & 0.048 & 0.36 \\
\hline Late effects & $0.03(-0.02 ; 0.09)$ & 0.285 & 0.03 \\
\hline Relapse & $0.00(-0.06 ; 0.05)$ & 0.883 & 0.03 \\
\hline Fear to detect late effects & $0.00(-0.07 ; 0.07)$ & 0.926 & 0.04 \\
\hline \multicolumn{4}{|l|}{ Measurement model } \\
\hline \multicolumn{4}{|l|}{ Attitude } \\
\hline Indicator_1: Meaningful & $0.66(0.55 ; 0.75)$ & $<0.001$ & 0.05 \\
\hline Indicator_2: Good & $0.69(0.60 ; 0.78)$ & $<0.001$ & 0.05 \\
\hline Indicator_3: Pleasant & $0.75(0.66 ; 0.85)$ & $<0.001$ & 0.05 \\
\hline Indicator_4: Interesting & $0.69(0.60 ; 0.78)$ & $<0.001$ & 0.05 \\
\hline Indicator_5: Important & $0.41(0.30 ; 0.53)$ & $<0.001$ & 0.06 \\
\hline \multicolumn{4}{|l|}{ Subjective Norm } \\
\hline Indicator_1: Pressure & $0.94(0.92 ; 0.96)$ & $<0.001$ & 0.01 \\
\hline Indicator_2: Expectation & $0.88(0.85 ; 0.91)$ & $<0.001$ & 0.02 \\
\hline \multicolumn{4}{|l|}{ Perceived Control } \\
\hline Indicator_1: Easy & $0.67(0.61 ; 0.80)$ & $<0.001$ & 0.05 \\
\hline Indicator_2: Not stressful & $0.83(0.70 ; 0.88)$ & $<0.001$ & 0.05 \\
\hline \multicolumn{4}{|l|}{ Intention } \\
\hline Indicator 1: Intention & $0.98(0.98 ; 0.99)$ & $<0.001$ & 0.00 \\
\hline Indicator 2: Probability & $0.99(0.98 ; 1.00)$ & $<0.001$ & 0.00 \\
\hline \multicolumn{4}{|l|}{ Covariance } \\
\hline \multicolumn{4}{|l|}{ Attitude } \\
\hline e.indicator_1, e.indicator_2 & $0.74(0.67 ; 0.81)$ & $<0.001$ & 0.00 \\
\hline e.indicator_3, e.indicator_4 & $0.31(0.14 ; 0.48)$ & $<0.001$ & 0.00 \\
\hline
\end{tabular}

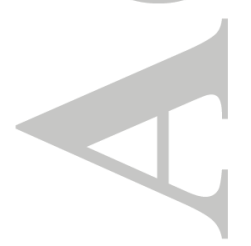

This article is protected by copyright. All rights reserved. 
Table 2. (continued)

\begin{tabular}{|c|c|c|c|c|}
\hline \multirow{2}{*}{ GoF Index ${ }^{a}$} & \multirow[t]{2}{*}{ Value } & \multicolumn{2}{|c|}{ Criterion } & \multirow[t]{2}{*}{ GoF } \\
\hline & & $\begin{array}{c}\text { good } \\
\text { fit }\end{array}$ & acceptable & \\
\hline $\mathrm{X}^{2}(\mathrm{df}, \mathrm{p}$-value $)$ & $221(99, \leq 0.001)$ & $\leq 2 \mathrm{df}$ & $\leq 3 \mathrm{df}$ & acceptable \\
\hline $\mathrm{X}^{2} / \mathrm{df}$ & 2.23 & $\leq 2$ & $\leq 3$ & acceptable \\
\hline $\operatorname{RMSEA}(90 \% \mathrm{Cl})$ & $0.064(0.053-0.076)$ & $\leq 0.05$ & $\leq 0.08$ & acceptable \\
\hline $\mathrm{SRMR}^{\mathrm{b}}$ & 0.055 & $\leq 0.05$ & $\leq 0.10$ & acceptable \\
\hline $\mathrm{CFI}$ & 0.956 & $\geq 0.97$ & $\geq 0.95$ & acceptable \\
\hline
\end{tabular}

Abbreviations : Cl; confidence interval; df, degree of freedom; RMSEA, Root Mean Square Error or Approximation; SRMR, Standardized Root Mean Square Residual; CFI, Comparative Fit Index; GOF, Goodness of Fit.

p-values $<0.05$ are indicated in bold.

${ }^{\mathrm{a}}$ Recommended criteria by [26]

${ }^{\mathrm{b}}$ Based on 247 observations as SRMR can only be obtained without missing values
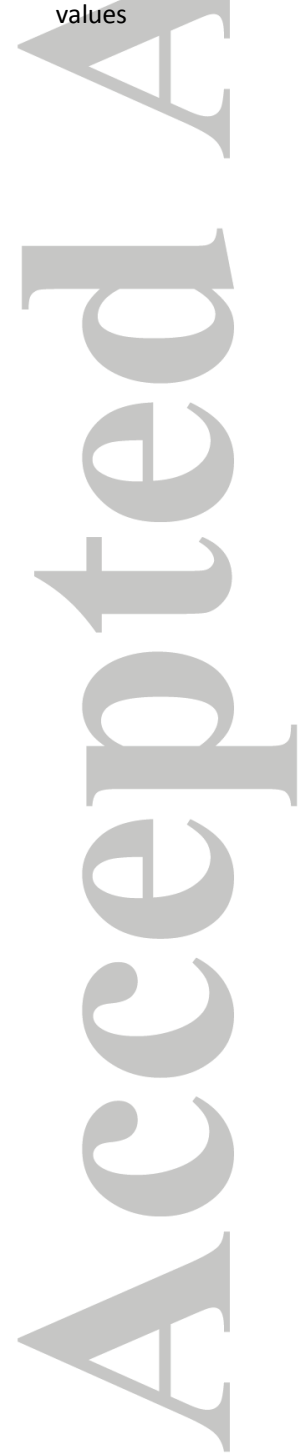
Structural Equation Model

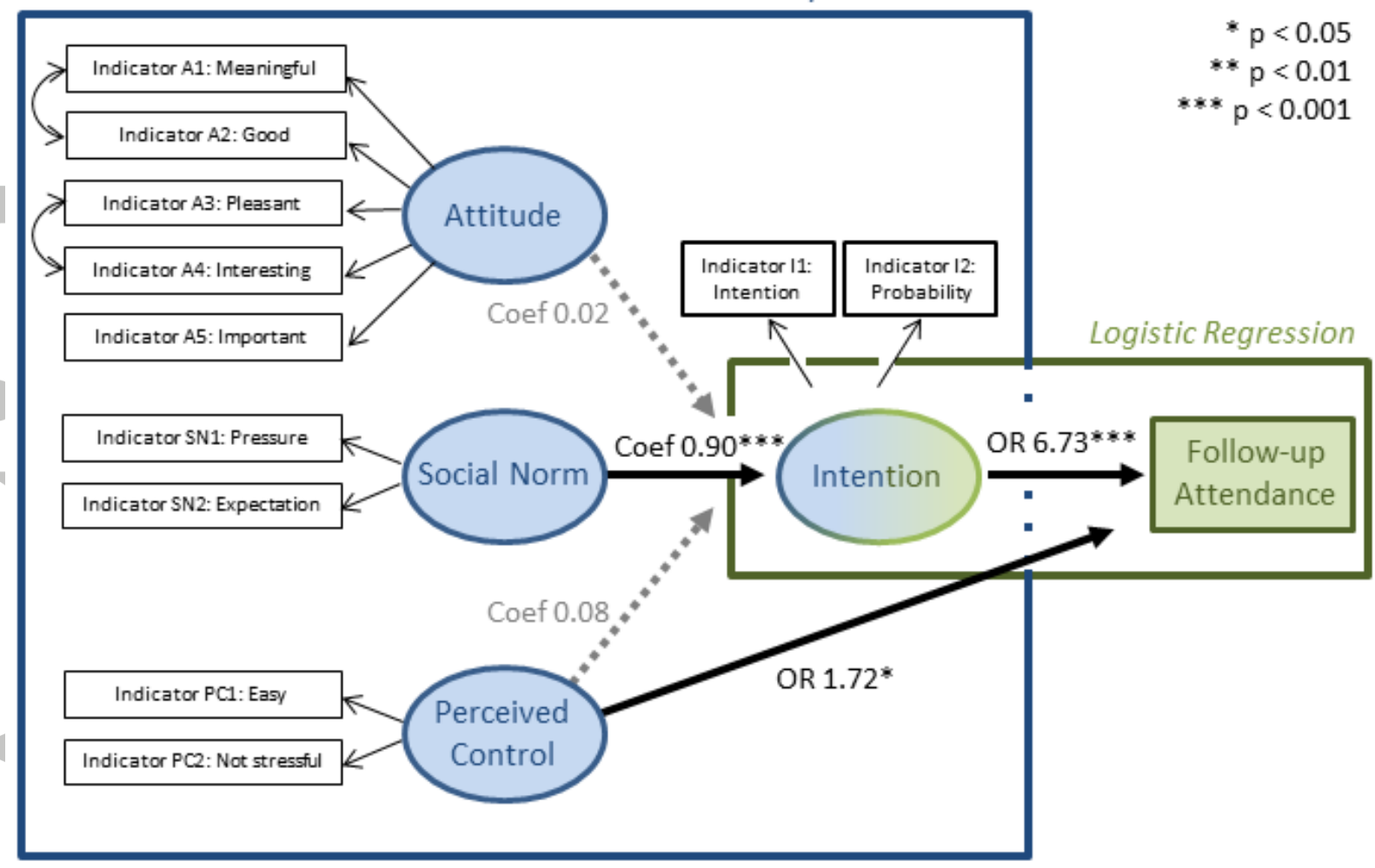

Figure 1. Attendance to follow-up care of Swiss childhood cancer survivors explained by the Theory of Planned Behavior using structural equation modeling (blue) and logistic regression (green).

Abbreviations: Coef, coefficient; OR, odds ratio.

Note: Model is adjusted for age at study, sex, education, treatment, age at diagnosis, time since diagnosis, late effects, relapse and fear to detect late effects. 